\title{
lodine excess in children with kidney disease: are we missing hypothyroidism?
}

\author{
Lesley Rees ${ }^{1}$ \\ Received: 18 March 2019 / Accepted: 20 March 2019 / Published online: 26 March 2019 \\ (C) IPNA 2019
}

Cohen et al. [1] report on iodine toxicity and hypothyroidism following micturating cystourethrography (MCUG) in two infants with CKD stage 5. The authors postulate that iodine in the contrast medium instilled into the bladder is absorbed and causes hypothyroidism. This is a very important observation, particularly in infants because of the role of thyroid hormones in cognitive development.

\section{Response of the thyroid gland to iodine excess}

The thyroid gland has evolved mechanisms to enable ongoing normal thyroid hormone production in the situation of iodine toxicity. Iodine excess exerts its effect on the thyroid gland in two ways. Firstly, when the intracellular iodide concentration reaches over $10^{-3} \mathrm{M}$, hormone synthesis is shut down. This is called the Wolff-Chaikoff effect. Subsequently, the sodiumiodide symporter, which transports iodide into thyroid cells, ceases to function. This means that the level of intracellular iodide drops and thyroid hormone production normalises after 24 to $48 \mathrm{~h}$ [2].

However, in some situations, there is a continuing deficiency in thyroid hormone production and hypothyroidism persists. Hypothyroidism may continue if the source of iodine is not removed and/or if renal clearance is abnormal. Hypothyroidism is common in neonates with congenital heart disease, who may be frequently exposed to iodine and in whom the link between iodine and hypothyroidism is well described. Such neonates can be exposed to large doses of intravenous (IV) iodinated contrast media during angiography, cardiac surgery and IV line insertions; iodine exposure may continue as iodine-soaked

Lesley Rees

Lesley.rees@gosh.nhs.uk

1 Department of Paediatric Nephrology, Great Ormond Street Hospital for Children NHS Foundation Trust, London WC1N 3JH, UK dressings may be applied to the sternum if it is not closed at the time of surgery. The iodine can then be absorbed into the circulation. Ongoing hypothyroidism occurs in around $25 \%$ of infants with congenital heart disease, and it has been suggested that the neonatal thyroid gland is immature, and particularly unable to restore normal thyroid function after an episode of iodine excess [3]. Of course, renal function is also immature in the neonate even without acute kidney injury, which is common in such infants. However, we know that hypothyroidism occurs after exposure to excess iodine in children of all ages and in adults too, particularly in situations of reduced renal function [4].

Reports of the incidence and duration of hypothyroidism following iodine excess vary from no effect, to an increase in TSH within 3-5 days with no effect on T4 and T3, to hypothyroidism between 50 and 294 days, to permanent hypothyroidism [5]. This variability is affected by the cumulative iodine dose received, whether the thyroid gland is normal or not, patient age (neonates are particularly vulnerable) and renal function. Iodine is excreted by glomerular filtration, with a half-life of around $2 \mathrm{~h}$ when renal function is normal. In a study in adults with normal renal function, looking at urinary iodine excretion following iodinated contrast medium administration for CT scans, the peak urinary iodine concentration occurred at 1.1 weeks and normalised by 5.2 weeks. Thyroid dysfunction developed in $22 \%$ [6]. Half-life increases as the GFR falls and can be as long as $30 \mathrm{~h}$ when renal function is severely impaired [5], so patients with CKD will have prolonged exposure to high blood levels of iodine after excess iodine exposure.

\section{Normal requirements for iodine}

There are guidelines for the recommended amount of iodine in the diet at different ages. Overall, the focus has been on iodine deficiency, and the WHO has published recommendations on salt-iodination. About $70 \%$ of households worldwide use iodised salt [7]. The UK recommended nutrient intake (RNI) is $0.5-1 \mathrm{mcmol}$ (63 $127 \mathrm{mcg} / \mathrm{day}$ ) [8] and is slightly higher in 
the USA (https://ods.od.nih.gov/factsheets/IodineConsumer/). Table 1 shows the recommended iodine intakes per day according to age in the USA, and Table 2 the recommended upper limit per day (https://ods.od.nih.gov/ factsheets/Iodine-Consumer/).

Dairy products are relatively high in iodine ( $50-80 \mathrm{mcg}$ per $200 \mathrm{ml}$ for cow's milk, 50-100 mcg per $150 \mathrm{~g}$ for yoghourt), followed by fish (50-115 mcg per $100 \mathrm{~g}$ ). Fruit and vegetables are the lowest at $3 \mathrm{mcg}$ per $80 \mathrm{~g}$. Feed supplements such as Paediasure contain $20 \mathrm{mcg}$ per $200 \mathrm{ml}$. There is no added iodine in vitamin supplements but vitamin and mineral supplements may contain from 75 to $169 \mathrm{mcg}$ per dose. Ninety percent of iodine absorbed orally is excreted in urine and the rest in the faeces [9].

\section{What can cause excess iodine?}

As little as $200 \mathrm{mcg}$ of iodine per day in adult studies can cause a fall in T4 and rise in TSH [2]. As well as oral intake, iodine can also be absorbed through the skin from iodinecontaining skin cleansers, particularly in neonates. These sources may contribute to iodine excess, but the best described cause of iodine toxicity is the use of IV-iodinated contrast media for radiological procedures such as CT scanning, angiography, venography, enema, IV urography, nephrostomy and MCUG. There are many different types of such agents, with variable iodine contents. For example, the commonest used in the UK is omnipaque (Iohexol), which comes in increasing strengths with iodine content varying from 140 to $300 \mathrm{mg}$ iodine per $\mathrm{ml}$. The largest doses are given IV during cardiac catheterisation. However, absorption can occur from the gut during enemas and across the urinary epithelium during procedures such as nephrostomy, IV urography and MCUG.

\section{Evidence for iodine excess causing hypothyroidism}

There are many studies of the effect of iodinated contrast media on the subsequent development of hypothyroidism, and results

Table 1 Recommended iodine requirements per day adapted from (https://ods.od.nih.gov/factsheets/Iodine-Consumer/)

\begin{tabular}{ll}
\hline Age & Recommended amount \\
\hline Birth to 6 months & $110 \mathrm{mcg}$ \\
$7-12$ months & $130 \mathrm{mcg}$ \\
$1-8$ years & $90 \mathrm{mcg}$ \\
$9-13$ years & $120 \mathrm{mcg}$ \\
$14-18$ years & $150 \mathrm{mcg}$ \\
Adults & $150 \mathrm{mcg}$ \\
\hline
\end{tabular}

Table 2 Recommended upper limit for iodine per day adapted from (https://ods.od.nih.gov/ Consumer/) factsheets/Iodine-

\begin{tabular}{ll}
\hline Age & Upper limit \\
\hline Birth to 12 months & Not established \\
1-3 years & $200 \mathrm{mcg}$ \\
4-8 years & $300 \mathrm{mcg}$ \\
$9-13$ years & $600 \mathrm{mcg}$ \\
14-18 years & $900 \mathrm{mcg}$ \\
Adults & $1100 \mathrm{mcg}$ \\
\hline
\end{tabular}

are predominantly affected by the presence of preceding thyroid abnormalities and renal dysfunction. Preceding thyroid dysfunction predisposes to the effects of iodine excess; and CKD in adults is associated with a high incidence of subclinical hypothyroidism even in patients who are not on dialysis [10]. On the other hand, a study of 33 infants without thyroid or renal abnormalities who were undergoing cardiac CT scans had their T3, T4 and TSH measured pre CT, $48 \mathrm{~h}$ after and at discharge at around 3 weeks of age. Although there was a fall in TSH at $48 \mathrm{~h}$, all levels had normalised at discharge [11].

Most of the descriptions of hypothyroidism are in neonates. Typically, the cases are infants undergoing procedures that require the use of iodinated contrast media for angiography, such as cardiac catheterisation or cardiac surgery. Between 1969 and 2012, the FDA Adverse Event Reporting System was notified of 11 cases of hypothyroidism associated with iodinated contrast media, ten of whom were less than 4 months of age and six had congenital heart disease. The average time to diagnosis of hypothyroidism following iodinated contrast medium administration was 15 days (range 7 to 30 days) (https://www.fda.gov/Drugs/DrugSafety/ucm472782.htm). Of three infants with congenital heart disease who developed hypothyroidism after exposure to iodinated contrast medium and iodine in surgical dressings, one had a spontaneous improvement in thyroid function; another received thyroid hormone replacement from day 14 to approximately day 23 of life; and the third was receiving thyroid hormone replacement at 15 months [12].

However, older children can be affected too: a large study in patients up to 18 years of age looked for evidence of the effect of iodinated contrast media on thyroid function by comparing 870 with thyroid dysfunction, defined as 2 consecutive TSH levels 6 months apart, with 870 with normal thyroid function. Patients were matched for age, sex and race. Sixtynine patients went on to receive contrast medium (53 with thyroid dysfunction, and 16 of the controls). The incidence of hypothyroidism was higher after contrast medium, with an odds ratio of 2.6. The interval between contrast and diagnosis of hypothyroidism was 10.8 months [13].

In the study by Cohen et al. [1], the putative source of iodine is MCUG. Iodine is known to be absorbed across the mucous membranes as well as the skin. The product guidelines for its use for MCUG recommend dilution of Iohexol to $50-100 \mathrm{mg} / \mathrm{ml}$ 
iodine (https://www.accessdata.fda.gov/drugsatfda_docs/label/ 2017/018956s099lbl.pdf). Even if only $30 \mathrm{ml}$ were to be introduced into the bladder, this would still be $1500 \mathrm{mg}$ to $3000 \mathrm{mg}$ iodine. High blood iodine levels have been reported before in children after MCUG [14]: blood iodine levels were well in excess of normal levels $(4-8 \mathrm{mcg} / \mathrm{dl})$. Those who were able to void and empty their bladder of contrast within a few minutes had the lowest blood levels $(8-650 \mathrm{mcg} / \mathrm{dl})$, but these were still above the normal range. Those who retained contrast in the bladder for 15-45 min and who had intrarenal reflux had levels of $6606-22,508 \mathrm{mcg} / \mathrm{ml}$ and those who had contrast in the bladder for 15 to $45 \mathrm{~min}$ but no intrarenal reflux had levels in between $(35-3030 \mathrm{mcg} / \mathrm{ml})$. Thirty four of the children in the study by Barr et al. [13] received contrast during an MCUG.

Another group of patients at risk of iodine excess are those on peritoneal dialysis (PD). The PD cap which is placed on the end of the PD catheter to prevent infection contains a sponge soaked in povidone iodine $10 \%$. This iodine can be washed into the child: three infants on PD diagnosed with hypothyroidism, which was known to have developed after a normal neonatal screen, had high plasma iodine levels. The authors investigated whether this was due to contamination from the cap by measuring the iodine in the dialysate in each cycle throughout the PD programme. Dialysate iodine concentrations were higher at the end of the first cycle than the twelfth cycle [15]. A second mechanism whereby iodine contamination of the cap might occur is after iodine has been used to soak it following disconnection. Usually, there is fluid in the abdomen so on reconnection the drainage from this flushes the iodine out. However, this would not be the case in a child with an empty abdomen and the iodine would be flushed instead into the abdominal cavity where it would be absorbed across the peritoneal membrane.

\section{Conclusion}

Reports of hypothyroidism and the role of iodine are sufficient to raise concern for the paediatric nephrology community. Who should we check, when and how often? Following the report by Cohen [1], should we be checking patients with CKD after MCUG? Should we check all patients who are given iodine containing contrast media for insertion of lines, venography and other procedures needing contrast, or just the newborn or those with severe CKD? Should we be using iodine-free cleansers or contrast media in our patients? What about contamination of the peritoneum in those on PD? These important questions demonstrate an urgent need for further studies before they can be answered.

\section{References}

1. Cohen L, Baudouin V, Ali L, Tanase A, Frerot A (2019) Voiding cystography, an unusual route of induced hypothyroidism by iodine overdose in two newborns with chronic kidney disease. Pediatr Nephrol

2. Burgi H (2010) Iodine excess. Best Pract Res Clin Endocrinol Metab 24:107-115

3. Thaker VV, Galler MF, Marshall AC, Almodovar MC, Hsu HW, Addis CJ, Feldman HA, Brown RS, Levine BS (2017) Hypothyroidism in infants with congenital heart disease exposed to excess iodine. J Endocr Soc 11:1067-1078

4. Leung A, Braverman LE (2014) Consequences of iodine excess. Nat Rev Endocrinol 10:136-142

5. Lee SY, Rhee CM, Leung AM, Braverman LE, Brent GA, Pearce EN (2015) A review: radiographic iodinated contrast media-induced thyroid dysfunction. J Clin Endocrinol Metab 100:376-383

6. Lee SY, Chang DLF, Xuemei He X, Pearce EN, Braverman LE, Leung AM (2015) Urinary iodine excretion and serum thyroid function in adults after iodinated contrast administration. Thyroid 25:471-477

7. World Health Organization (2014) Fortification of food-grade salt with iodine for the prevention and control of iodine deficiency disorders. Guideline. https://www.who.int/nutrition/publications/ guidelines/fortification_foodgrade_saltwithiodine/en/. Accsessed march 2019

8. Department of Health. Dietary reference values for food, energy and nutrients in the United Kingdom no. 41. London: HMSO; 1991

9. Jahreis G, Hausmann W, Kiessling G, Franke K, Leiterer M (2001) Bioavailability of iodine from normal diets rich in dairy productsresults of balance studies in women. Exp Clin Endocrinol Diabetes 109:163-167

10. Sanai T, Okamura K, Rikitake S, Fukuda M, Onozawa K, Sanematsu M, Takashima T, Miyazono M, Ikeda Y (2017) The high prevalence of reversible subclinical hypothyroidism with elevated serum thyroglobulin levels in chronic kidney disease patients. Clin Nephrol 87:237-244

11. Belloni E, Tentoni S, Puci MV, Avogliero F, Della Latta D, Storti S, Alberti B, Bottoni A, Bortolotto C, Fiorina I, Montomoli C, Chiappino D (2018) Effect of iodinated contrast medium on thyroid function: a study in children undergoing cardiac computed tomography. Pediatr Radiol 48:1417-1422

12. Thaker VV, Leung AM, Braverman LE, Brown RS, Levine B (2014) Iodine-induced hypothyroidism in full-term infants with congenital heart disease: more common than currently appreciated? J Clin Endocrinol Metab 99:3521-3526

13. Barr ML, Chiu HK, Li N, Yeh MW, Rhee CM, Casillas J, Iskander PJ, Leung AM (2016) Thyroid dysfunction in children exposed to iodinated contrast media. J Clin Endocrinol Metab 101:2366-2370

14. Currarino G, Weinberg A, Putnam R (1977) Resorption of contrast material from the bladder during cystourethrography causing an excretory urogram. Radiology 123:149-150

15. Brough R, Jones C (2006) Iatrogenic iodine as a cause of hypothyroidism in infants with end-stage renal failure. Pediatr Nephrol 21:400-402

Publisher's Note Springer Nature remains neutral with regard to jurisdictional claims in published maps and institutional affiliations. 